\title{
MÍDIA IMPRESSA E ELETRÔNICA: UMA ANÁLISE SOB A ÓTICA DO VALOR PARA O CLIENTE NA GESTÃO DE PRODUTOS
}

\author{
Áurea Helena Puga Ribeiro \\ Doutora em Administração de Empresas pela Fundação Getúlio Vargas - FGV \\ Professora da Fundação Dom Cabral - FDC \\ aureap@fdc.org.br (Brasil)

\section{Plínio Rafael Reis Monteiro} \\ Doutor em Administração pela Universidade Federal de Minas Gerais - UFMG \\ Professor do Centro de Pesquisas e Pós Graduação em Administração (CEPEAD/UFMG) \\ preis@ face.ufmg.br (Brasil)
}

\section{Fernando Dias Martins}

Mestre em Administração pela Pontifícia Universidade Católica de Minas Gerais - PUC/MG fmartins@contentstuff.com (Brasil)

\section{RESUMO}

Este estudo buscou entender o comportamento do consumidor em relação ao valor gerado pelas versões impressa e eletrônica de uma revista, com o objetivo de compreender como a natureza da informação fornecida por estes produtos complementares contribui para a lealdade e a satisfação dos consumidores. A metodologia aplicada e descrita ao longo deste trabalho foi baseada em um estudo de caso de um blog do mercado brasileiro utilizando uma abordagem conclusiva. Uma amostra composta por 487 assinantes da revista foi examinada e os resultados preliminares mostram que a versão eletrônica da revista, em isolado, ainda é um produto de baixo valor agregado para os leitores. Além disso, verificou-se que a versão eletrônica agrega valor para a versão impressa, sendo valorizada pela maioria dos assinantes da revista impressa. A versão eletrônica aparece como um produto complementar ao produto impresso e não um produto de substituição. $\mathrm{O}$ estudo também mostrou que o modelo hipotético de relações entre satisfação, valor e lealdade é consistente com a teoria que mostra uma correlação razoável entre essas duas dimensões do produto.

Palavras-chave: Valor percebido; Lealdade; Gestão de produtos. 


\section{INTRODUÇÃ̃O}

Em um cenário em que prevalece a diversificação e criação de múltiplos canais de relacionamento, questionamentos acerca dos papéis de diferentes formas de atendimento ao consumidor e suas implicações mercadológicas se tornam prementes. Desse modo estratégias de extensão de linhas ou diversificação de produtos estão sempre atreladas ao risco de canibalização ou oportunidade de complementaridade.

O setor de mídia impressa vem observando tais questionamentos de forma nítida, a partir do crescimento das formas eletrônicas de comunicação. $\mathrm{O}$ aumento da abrangência da Internet a partir do final dos anos 90 trouxe novas oportunidades e desafios para essa indústria, que tem seus modelos econômicos sustentados por dois tipos principais de receita: o mercado leitor e o mercado anunciante. A mídia impressa dispõe de um grande acervo de conteúdo que pode ser disponibilizado com certa facilidade para o meio eletrônico, possibilitando a criação de um fluxo contínuo de conteúdo interessante e atualizado para acesso através da Internet.

Alguns estudos apontam que não há canibalização entre o meio impresso e o eletrônico. Entretanto, mostram queda progressiva no tempo em que o americano médio consome mídia impressa, enquanto o tempo de consumo de mídias eletrônicas, notadamente a Internet, vem crescendo ano a ano. A previsão é que se mantenha a tendência de crescimento do consumo de mídia total no mercado americano, com grande crescimento da Internet em detrimento da mídia impressa, que permanece com seu tempo de consumo em queda.

Uma possível estratégia nesse mercado é a de reposicionar o negócio tradicional impresso para aumentar a utilização dos ativos da empresa na Internet a fim de absorver parte do crescimento desse meio. Entretanto, faz-se relevante questionar se os leitores tenderão a buscar conteúdo e entretenimento na Internet em vez de buscá-lo nas mídias tradicionais. Até que ponto essa alternativa pode competir com o próprio jornal ou revista impressos?

Essas questões colocam novas perguntas sobre a relação da mídia impressa e sua versão eletrônica. As duas mídias podem se complementar, gerando benefícios tanto para a versão impressa quanto eletrônica? A mídia eletrônica pode competir com a mídia impressa tradicional, caminhando para substituí-la? O consumidor avalia a mídia impressa e a mídia eletrônica da mesma forma ou os fatores utilizados para avaliar valor, satisfação e lealdade se relacionam de forma diferente para os dois tipos de mídia? As relações entre os construtos valor, satisfação e lealdade são equivalentes para as mídias na versão impressa e na versão eletrônica?

Revista de Administração e Inovação, São Paulo, v. 11, n.1, p.06-28, jan./mar. 2014. 
Assim, compreender o comportamento do consumidor em relação à versão impressa e à versão eletrônica de um veículo de comunicação faz-se fundamental para apoiar as decisões gerenciais nessa indústria e justifica a relevância da presente pesquisa.

\subsection{Objetivos da Pesquisa}

O objetivo geral da pesquisa é identificar a relevância das versões impressa e eletrônica para o consumidor de mídia, bem como compreender se há congruência no comportamento do consumidor da versão impressa e da versão eletrônica.

Sendo assim, definem-se como objetivos específicos:

avaliar se as relações entre os construtos valor, satisfação e lealdade são equivalentes para a revista na versão impressa e na eletrônica;

$>$ avaliar se os fatores utilizados para apreciar os construtos valor, satisfação e lealdade se relacionam de forma similar para a revista na versão impressa e na eletrônica.

\section{REFERENCIAL TEÓRICO}

\subsection{O comportamento do consumidor de mídias eletrônicas}

Cole, Suman, Schramm, Zhou e Salvador, (2013) estudaram o padrão de atividades off-line e compararam o comportamento dos usuários de Internet com os não usuários. Pesquisas recentes apontam, nos Estados Unidos, que o usuário médio de Internet fica online 12,5 horas por semana e consome menos tempo em mídias tradicionais do que os não usuários. No consumo de mídia impressa - jornais, revistas e livros - por exemplo, os usuários de Internet gastam 40\% menos tempo lendo jornais do que os não usuários. E, respectivamente, $35 \%$ e $15 \%$ menos tempo lendo revistas e livros. A redução do tempo gasto com televisão é o mais expressivo em termos absolutos: os internautas consomem 4,6 horas a menos de TV do que os não usuários (Cole et al., 2013).

Revista de Administração e Inovação, São Paulo, v. 11, n.1, p.06-28, jan./mar. 2014. 

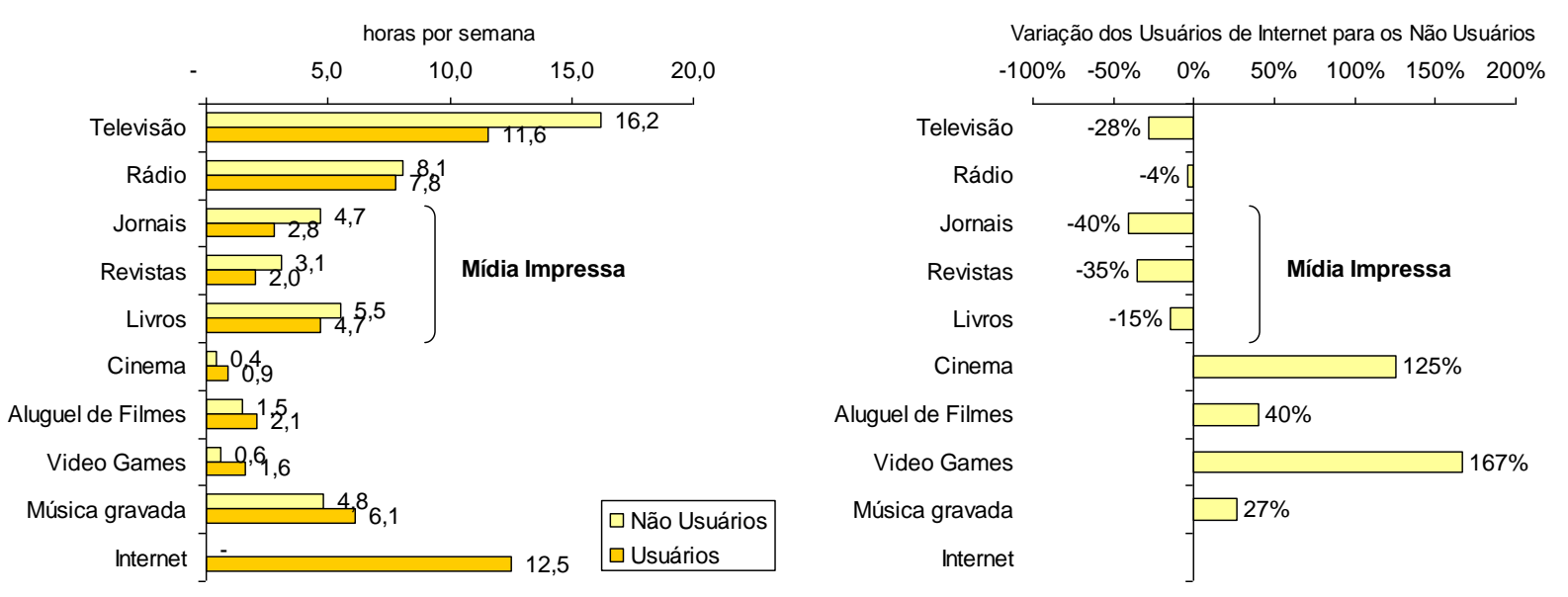

Figura 1 - Utilização de mídias nos EUA entre usuários e não usuários de Internet Fonte: Adaptado de Cole et al., 2004. (2013, p. 46.)

Os resultados do estudo de Cole et al. (2013) quanto à redução do tempo dedicado a outras mídias é convergente com os estudos de Dimmick, Chen e Li (2004) e de Mori Research (2004). O primeiro verificou que $32 \%$ dos usuários de sites de jornais dizem que usam menos o jornal impresso, e o segundo mostrou que a Internet apresenta um efeito de substituição sobre a televisão e os jornais. Da mesma forma Lebo (2004) compilou estudos realizados em vários países e concluíram que, em todos eles, os usuários de Internet gastam menos tempo com a televisão do que entre os não usuários. Os países pesquisados foram Inglaterra, Chile, Alemanha, Hungria, Japão, Coreia do Sul, China, Singapura, Suécia e Taiwan.

Pelas análises que foram tecidas anteriormente, pôde-se verificar que os efeitos da Internet não são um acontecimento pontual, mas uma tendência crescente. Nesse contexto, uma migração da cadeia de valor ancorada no mundo físico - com a impressão do conteúdo em papel -, para o mundo virtual com a entrega do mesmo conteúdo através da Internet -, poderia levar a grandes economias em custos variáveis com a eliminação do custo de compra de papel, tinta, serviços de impressão e logística de distribuição. Esse tipo de transição é apontado por Rayport e Sviokla (1995) como potencializador de economias de escala, um dos novos princípios da cadeia virtual de valor.

Dhingra, Buisson, Gil-Casares e Raynaud-Lacroze (2001, p. 5) adicionam que a Internet é uma mídia com encaixe perfeito para os jornais e revistas. Os autores justificam que, sendo o produto a informação, pode ser facilmente digitalizado e distribuído através da Internet. E por tratar-se de notícias, é sensível ao tempo, e a rápida distribuição através da Internet é de valor para os clientes. Além disso, os clientes são geralmente mais educados e possuem renda mais alta, o que leva a uma proporção maior desse tipo de cliente com acesso à Internet. 
A canibalização pela Internet parece algo inerente à publicação de revistas e jornais. A oportunidade para as empresas do setor pode ser buscar alguma forma de migração de seu atual modelo de negócios para a Internet (Barsh, Lee \& Miles, 1999). Entretanto, Barsh, Lee e Miles et al. (1999, p. 123), assim como Gren, Maor e Ubiñas (2001),) sugerem que um modelo híbrido combinando a revista impressa e a presença na Internet possibilitaria que as empresas se tornassem mais fortes do que se dependessem apenas da mídia tradicional, convergindo as mídias de forma complementar na tentativa de contrabalançar aspectos positivos e negativos de cada uma.

\subsection{Geração de valor e lealdade nas versões impressa e eletrônica}

Para os editores de jornais e revistas, considerar a Internet como mídia relevante parece um imperativo. Entretanto, será que o consumidor de informações se comporta de forma similar perante a mídia tradicional (revista) e a mídia eletrônica? Valorizam os mesmos atributos e com a mesma intensidade dos atributos ofertados na mídia impressa?

Para o estudo do comportamento do leitor frente a essas duas mídias, dois construtos - valor e lealdade - são aspectos fundamentais que merecem atenção.

A entrega de valor para os clientes é citada como a forma para a construção de negócios de sucesso, sendo também a base da ciência do marketing. (Grönroos, 1997; Holbrook, 1994; Ravald \& Grönroos, 1996). A entrega de valor em negócios online através da disponibilização de conteúdos e serviços também vem sendo sugerida como fator fundamental para a criação de sites de sucesso na Internet (Breitenbach \& Van Doren, 1998; Rayport \& Sviokla, 1995).

Rayport e Sviokla (1995) defendem que os processos para criar valor não são os mesmos no mundo off-line - físico - e no mundo online - virtual. Assim, entender as diferenças do comportamento do consumidor na valorização dos conteúdos lidos a partir do produto impresso e a partir dos produtos acessados através da Internet é uma atividade importante para calibrar a forma de utilização dessas duas mídias pelas empresas jornalísticas.

A conquista da lealdade dos leitores é outro ponto fundamental para os editores. Conforme apontam Barsh, Lee e Miles et al. (1999), os leitores mais leais tendem a renovar suas assinaturas quase que de forma automática, por períodos mais longos que um ano, e tendem a pagar os preços mais altos. A entrega de valor é um caminho para a criação de uma base de leitores fiéis, o que é fundamental para a rentabilidade do negócio de publicação de revistas (Barsh et al., 1999; Berry \& Parasuraman, 1991; Kordupleski \& Simpson, 2003; Oliver, 1999; Ravald \& Grönroos, 1996).

Revista de Administração e Inovação, São Paulo, v. 11, n.1, p.06-28, jan./mar. 2014. 
Entender que atributos de valor contribuem para a construção da lealdade dos leitores e comparar o resultado disso nas duas versões do produto - revista impressa e revista eletrônica - é um ponto importante para estabelecer as estratégias de negócios dos editores nessas duas plataformas e é um dos objetivos deste trabalho.

\subsubsection{O conceito de valor}

Os estudos mais recentes têm apresentado duas abordagens básicas para o construto valor: valor de troca e valor em uso. As definições clássicas de marketing (KOTLER, 1997, 2000), predominantes até meados da década de 90, fundamentam-se no conceito de valor de troca. Em completa harmonia com a abordagem de troca, Kotler e Keller (2012, p. 10) define valor como "a soma de todos os benefícios tangíveis e intangíveis em satisfazer suas necessidades”. Nessarelação aos custos”. Nesta definição encontra-se a premissa da existência de um valor absoluto, objetivo, que independe de quem usa o produto ou serviço. Entretanto, Zeithaml (1998) define o valor percebido pelo cliente como sua avaliação geral da utilidade do produto com base na sua percepção do que é recebido em troca do que é dado. Portanto, de acordo com a autora, valor é relativista, varia de pessoa a pessoa, situações e uso.

Holbrook (1994) discute essa questão profundamente. Ele aborda as duas linhas extremas que permeiam a definição de valor: o objetivismo e o subjetivismo. Em uma abordagem subjetivista, o valor é completamente dependente e relativo à experiência humana, enquanto que em uma abordagem objetivista, o valor existe antes da ação de valorização e, assim, não é dependente da avaliação das pessoas. Entretanto, o autor defende uma posição intermediária, em que o valor envolve uma relação entre o objeto e o sujeito e, portanto, requer tanto um consumidor quanto um produto.

Em decorrência da discussão, tanto Oliver (1999) quanto Holbrook (1994) apresentam uma distinção entre os conceitos de valor como excelência e valor como eficiência ou valor como performance.

Na concepção de Oliver (1999), o valor como excelência está diretamente relacionado à qualidade do produto. Portanto, por sua característica reativa, Oliver (1999) afirma que o valor como excelência é percebido em dois momentos no comportamento do consumidor: no período que antecede a compra e no período pós-consumo, períodos em que o consumidor não opera diretamente sobre o produto ou serviço.

O valor como eficiência ou como performance é definido por Holbrook (1994, p. 44) como "um valor extrínseco que resulta da manipulação ativa de quem usa (um meio), em busca de algum fim auto-orientado" e acrescenta que "a eficiência é, portanto, inseparável do ato do uso do produto para

Revista de Administração e Inovação, São Paulo, v. 11, n.1, p.06-28, jan./mar. 2014. 
atingir algum propósito em interesse próprio". Oliver (1999) avalia que o valor como eficiência acontece no período ativo do comportamento do consumidor, ou seja, no ato do consumo em si.

Assim, Holbrook (1994, p. 37) aponta que valor está relacionado a uma experiência, sustentando que o "valor no comportamento do consumidor não reside no objeto (produto ou serviço) comprado, mas se relaciona diretamente à experiência de consumo dele derivada".

Outros autores têm-se preocupado em compreender o valor gerado durante o processo de uso e as suas consequências. Woodruff (1997) foi um dos importantes pesquisadores que relacionou os construtos valor em uso e satisfação. Em seu estudo o autor sugere que os gestores devem privilegiar o gerenciamento de valor de uso em vez de satisfação, uma vez que análise de valor permite uma avaliação objetiva em relação aos atributos desejados dos produtos e atributos relativos à performance esperada.

Em estudos realizados em mercados organizacionais, o valor como performance, por depender do conhecimento do contexto de uso, é potencializado pela intensidade da relação entre as partes e ao mesmo tempo sustenta os relacionamentos de longo prazo (Eggert \& Ulaga, 2002; Steenkamp \& Geyskens, 2012). Em trabalhos desenvolvidos por Berry et al., Carbone e Haeckel (2003) e Pine II e Gilmore (1999) os autores exploram o valor gerado na experiência de consumo em mercados consumidores e estes estudos sugerem sua relevância para a lealdade do cliente. Ribeiro (2005), encontraram em uma pesquisa empírica entre pacientes internados em um hospital que o valor percebido na experiência de consumo (valor como performance) relaciona-se diretamente à lealdade e ao valor como excelência, além de anteceder à percepção de valor como performance.

\subsubsection{O conceito de lealdade}

A lealdade tem-se tornado um tema bastante discutido atualmente tanto na academia quanto nas empresas. A busca de clientes que sejam menos suscetíveis a promoções de concorrentes, que estejam dispostos a pagar preços maiores e que façam referências positivas dos produtos da empresa desperta a atenção de todos.

Oliver (1999, p. 392) apresenta uma definição para o conceito de lealdade: "A lealdade do cliente é um comprometimento profundo em realizar a recompra de um produto ou serviço preferido consistentemente no futuro, mesmo com influências situacionais e esforços de marketing com potencial de causar a mudança de comportamento".

Para o autor, a lealdade ocorre em quatro níveis distintos e hierárquicos: lealdade cognitiva, afetiva, conativa e ativa. A lealdade cognitiva é a primeira fase da lealdade, baseada apenas na

Revista de Administração e Inovação, São Paulo, v. 11, n.1, p.06-28, jan./mar. 2014. 
cognição do cliente, que usa a base de informações disponíveis para a escolha de uma marca sobre a outra; a lealdade afetiva é a segunda fase de lealdade, caracterizada pelo comprometimento, em que a lealdade já fica codificada na mente do consumidor com afeto e não apenas de forma cognitiva; a lealdade conativa é o terceiro estágio, que mostra a dimensão de intenção comportamental da lealdade, em que o cliente demonstra um profundo comprometimento em comprar, e a lealdade ativa é o estágio final, em que a lealdade é sustentada por comprometimento e inércia de ação. Nesta fase, a intenção acompanhada da motivação faz com que o cliente esteja pronto a agir e disposto a sobrepor obstáculos para tomar a ação de compra.

Segundo o modelo de Oliver (1999), a ampliação da força da lealdade ocorre ao longo dos quatro níveis sugeridos. No estágio cognitivo, a lealdade ainda é fraca: outra empresa oferecendo algum tipo de informação mais atraente pode causar a mudança de marca pelo cliente. No estágio seguinte, da lealdade afetiva, a relação do cliente com a marca se torna mais forte, como analisa Oliver (1999, p. 393): “a cognição é diretamente sujeita a contra-argumentação enquanto o afeto é incorporado e, portanto, ancorado à cognição e à avaliação geral da marca realizada pelo consumidor”.

$\mathrm{O}$ autor defende que, a fim de se conquistar a lealdade verdadeira dos clientes, deve-se empreender em levar os clientes a passos adicionais na escala de lealdade, já que a cognição e afeição não são suficientes para evitar a deserção de clientes, o que caracteriza a quebra da lealdade. O passo seguinte, então, é o da lealdade conativa, caracterizada pela intenção e comprometimento comportamental. Oliver (1999, p. 393) indica que "o afeto sugere apenas uma propensão motivacional, enquanto o comprometimento comportamental implica num desejo em se esforçar para tomar ação". Nesse passo há o desejo da recompra da marca e de ser leal a ela, porém ainda se caracteriza como uma ação ainda não realizada. O último passo, então, é justamente o cliente estar pronto para ação e disposto a transpor obstáculos para realizar a compra, atingindo aí a verdadeira lealdade, que é a lealdade ativa.

\subsection{As relações entre valor, satisfação e lealdade}

Os modelos teóricos que relacionam valor e satisfação geralmente possuem construtos consequentes que se referem às intenções comportamentais. A lealdade é um construto que vários autores têm analisado como consequência da percepção de valor e da satisfação (Labarbera \& Mazursky, 1983, Newman \& Werbel,1973; Rust, Zhorik \& Keiningham, 1995; Zeithaml \& Bitner, 2003).

Revista de Administração e Inovação, São Paulo, v. 11, n.1, p.06-28, jan./mar. 2014. 
Existe certa discussão se a satisfação é um tipo de valor ou um conceito separado. Oliver (1999) argumenta que valor e satisfação devem ser avaliados como conceitos relacionados, porém distintos. "Valor e satisfação mutuamente se influenciam. (...) Ambos têm antecedentes comuns no evento do consumo, como a performance de um produto ou serviço, e ambos têm consequências comuns, como a lealdade" (Oliver, 1999, p. 58). Entretanto, em seu estudo, Oliver (1999) sustenta que satisfação pode existir na ausência de valor e que valor pode existir na ausência de satisfação, o que justifica a separação desses dois conceitos.

Pesquisas empíricas identificaram que satisfação é o principal motivador da lealdade dos clientes (Labarbera \& Mazursky, 1983; Newman \& Werbel, 1973; Rust \& Zahorik, 1993). Outros autores sustentam que, para fins de desenvolvimento de relacionamento com o cliente, é melhor gerenciar valor e não satisfação (Eggert \& Ulaga, 2002).

Newell (2002) identificou no mercado certa confusão na maneira como as empresas buscam conquistar a lealdade dos consumidores. Algumas empresas tentam comprar a lealdade através de descontos, pontos e programas de fidelidade, enquanto outras tentam ganhar os clientes provendo valor em formas que sejam significantes para o cliente individual, nos termos de cada um. Entretanto, Newell (2002, p. 27) alerta que só há uma forma para a conquista da lealdade: "Aprendemos que você não pode comprar a lealdade dos clientes" e, portanto, ela deve ser construída através da entrega de valor.

\subsection{O Valor como antecedente para a construção da lealdade}

Como discutido anteriormente, a satisfação dos clientes está relacionada à lealdade, porém estudos indicam que ela não é suficiente para a conquista da lealdade dos consumidores (Oliver, 1999; Reichheld, 1993). Labarbera e Mazurski (1983), por exemplo, concluíram em seu estudo que a importância relativa da satisfação em predizer a recompra parece diminuir conforme a lealdade aumenta. Oliver (1999), em acordo com essas afirmações, cita o estudo de Reichheld (1993). Nesse estudo Reichheld (1993) conclui que entre $65 \%$ e $85 \%$ dos clientes que desertam dizem que estavam satisfeitos ou muito satisfeitos com seu fornecedor anterior. $\mathrm{Na}$ indústria automobilística, os indicadores de satisfação ficam em média entre $85 \%$ e $95 \%$, enquanto a taxa de recompra fica em média em apenas $40 \%$. Os atuais sistemas de medição de satisfação não são desenhados para prover ideias de quantos clientes permanecem leais à empresa, nem por quanto tempo.

Outros autores também apresentam controvérsias em relação à satisfação como antecedente da lealdade. Swaddling e Miller (2002), por exemplo, apesar de reconhecerem vantagens e desvantagens

Revista de Administração e Inovação, São Paulo, v. 11, n.1, p.06-28, jan./mar. 2014. 
nos modelos de medidas da satisfação dos clientes como antecedente de lealdade, afirmam que o valor percebido pelo cliente comparado aos concorrentes é que deve ser utilizado como o melhor preditor da lealdade. Segundo os autores, a satisfação dos clientes, por ser medida considerando expectativas formadas pelo cliente, principalmente em decorrência de experiências passadas, não é adequada para analisar o comportamento de clientes potenciais e futuras experiências. Para esses mesmos autores, a satisfação é reflexo somente da avaliação das características do produto ou serviço considerando suas referências internas. Além disso, segundo os autores, os atributos mensurados na satisfação dos clientes são relativos somente às características dos produtos ou serviços, enquanto que a medida de percepção de valor do cliente envolve atributos relacionados aos benefícios e custos percebidos no processo de compra.

O valor, portanto, é citado por vários autores como antecedente da lealdade (Berry \& Parasuraman, 1991; Newell, 2002; Oliver, 1999; Ravald \& Grönroos, 1996). Berry \& Parasuraman (1991, p. 148), em seus estudos sobre o marketing de relacionamento, comentam que o valor “determina o nível, e a força, dos relacionamentos entre empresa e cliente".

Assim, valor é uma importante dimensão para a construção da lealdade com os clientes e contribui com o desenvolvimento de negócios com vantagem competitiva sustentável. E, pelo exposto, a entrega de valor na Internet também é uma dimensão importante a ser observada para as empresas que queiram utilizar essa mídia.

\subsection{Hipóteses de trabalho e modelo da pesquisa}

Como discutido ao longo do documento, esta pesquisa analisa o comportamento do leitor frente ao conteúdo de uma revista em duas mídias diferentes: a revista impressa e o seu site, representando a versão eletrônica da revista. Os dois pontos focais da aplicação da pesquisa empírica são relacionados à compreensão da percepção de valor do consumidor (o leitor) da versão impressa e eletrônica da revista e o impacto em sua relação de lealdade com cada uma das versões do conteúdo da revista. Pela revisão da literatura, foi identificado que a percepção de valor está diretamente relacionada à lealdade.

Seguindo a tipologia de Holbrook (1994), o construto do Valor Percebido foi desdobrado em dois tipos de valor, pertinentes ao presente estudo: Valor como Eficiência e Valor como Excelência.

O valor como excelência por ser auto-orientado é relacionado a uma resposta reativa do cliente. Pela análise de Oliver (1999), o valor como excelência é gerado em momentos em que o consumidor não opera diretamente sobre o produto ou serviço, se associando a uma resposta reativa de admiração prévia à experiência de consumo. Sua natureza funcional reflete-se diretamente na geração

Revista de Administração e Inovação, São Paulo, v. 11, n.1, p.06-28, jan./mar. 2014. 
de vínculos duradouros entre o consumidor e o produto. Desse modo propõe-se a seguinte hipótese de pesquisa:

\section{$H_{1}$ - Há uma relação positiva entre valor como excelência e lealdade}

Holbrook (1994) sugere que além de ser gerado em momentos anteriores ao consumo o valor poderia emergir durante a própria experiência de consumo. Denominando este de valor como eficiência, percebe-se ser indissociável do modo como o produto ou serviço possibilita ao usuário o alcance de objetivos próprios. Tipicamente esse valor se liga a elementos de facilidade de uso e disponibilidade, ou seja, conveniência. Oliver (1999) destaca que tais elementos do construto valor são fontes primordiais de vínculos afetivos e lealdade do consumidor. Portanto interpõe-se a seguinte hipótese de pesquisa:

\section{$H_{2}$ - Há uma relação positiva entre valor como eficiência e lealdade}

Na literatura de comportamento do consumidor são recorrentes as associações entre satisfação e lealdade do consumidor (Fornell, 1992; Morgan \& Hunt, 1994; Oliver, 1999). Essa relação entre satisfação e lealdade remonta a um dos fundamentos da disciplina de marketing, especialmente nas temáticas de serviços e relacionamentos (Cronin \& Taylor, 1992). Tal constatação leva à proposição da terceira hipótese do trabalho.

\section{$H_{3}$ - Há uma relação positiva e significativa entre satisfacão e lealdade}

Deve-se salientar que a pesquisa buscou comparar a revista impressa com seu site. Deste modo, se busca salientar diferenças entre as duas dimensões do produto, isto é, os produtos base e o produto ampliado, permitindo obter evidências favoráveis ou contrárias à congruência na relação do leitor com a revista impressa e a eletrônica. Pode-se, portanto, desenhar o modelo hipotético proposto no item anterior em duas dimensões. 


\section{METODOLOGIA}

A pesquisa quantitativa aplicada foi realizada utilizando como unidade de análise uma revista do mercado brasileiro. Este produto editorial, que é tratado ao longo do documento como Revista Filhos por questões de confidencialidade, é uma publicação relacionada à puericultura, com conteúdos tratando desde os cuidados durante a gravidez até os primeiros anos de vida dos filhos.

A Revista Filhos é publicada mensalmente desde 1997 e possui um site que foi lançado no início de 2004. O site publica mensalmente todo o conteúdo da revista impressa seguindo um modelo de acesso ilustrado na figura a seguir. Parte do conteúdo tem seu acesso livre a todos os internautas. Uma segunda parte do conteúdo é acessível gratuitamente, porém apenas aos internautas que se cadastram no site da revista. O restante do conteúdo da revista é disponibilizado apenas aos assinantes da revista impressa. A Figura 2 a seguir ilustra o modelo de acesso ao conteúdo da Revista Filhos na Internet.

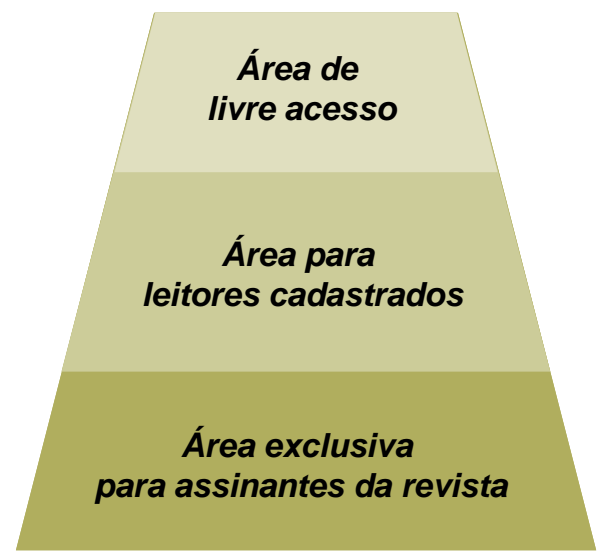
Uma pequena parte do conteúdo é disponibilizada para qualquer internauta, independentemente de ser assinante ou leitor cadastrado - de 1 a 3 matérias por edição
Apenas leitores que se cadastram na newsletter da revista (e assinantes) podem acessar essas matérias - de 10 a 15 matérias por edição
Apenas assinantes têm acesso ao conteúdo especial do site, composto pelo restante das matérias da edição (de 10 a 15 matérias por edição) e por material exclusivo como o dicionário de nomes e o guia do bebê

Figura 2 - Esquema da disponibilização do conteúdo no site da Revista Filhos

Fonte: Elaborada pelos autores.

Essa mecânica de disponibilização de conteúdo no site vem propiciando à revista um volume significativo de vendas de novas assinaturas da revista impressa pela Internet. A coleta de dados foi feita através de um link para o questionário no site da revista.

O questionário continha avaliações das duas mídias (eletrônica e impressa) utilizando escalas similares adaptadas de Puga, Hanna, Monteiro e Veiga (2008) e Oliver (1999). O instrumento foi composto por 34 indicadores, 17 para cada mídia. Os itens foram avaliados em escalas forçadas e equilibradas do tipo Likert com cinco alternativas (Malhotra, 2012). Os construtos apresentaram múltiplos itens, exceto o construto satisfação, avaliado com somente um item geral, em conformidade com a proposição do modelo C-OAR-SE (Rossiter, 2002). Os conceitos mensurados para mídia 
impressa e eletrônica foram adaptados de modo a representar as especificidades de cada mídia. Foi elaborado um questionário eletrônico com link no próprio site da revista para leitores que tiveram acesso à área exclusiva para assinantes do site.

\subsection{Descrição do perfil da amostra}

Após três semanas de coleta, computou-se um total de 548 acessos à página inicial da pesquisa. Entretanto, em função do tamanho do questionário, era esperada certa queda do nível de respostas ao longo do preenchimento das páginas pelos respondentes, obtendo-se uma amostra inicial de 487 respondentes. O público foi composto prioritariamente de mães (75\%) com idade inferior a 35 anos (75\%) com nível de graduação ou mais $(77 \%)$.

A grande maioria dos participantes (74\%) já usava a Internet há mais de três anos e $66 \%$ têm o hábito de acessar a Internet diariamente, principalmente em casa (79\%) e no trabalho (68\%). Além disso, 33\% dos respondentes afirmam acessar o site a cada nova edição da revista impressa, demonstrando conhecimento sobre o produto no site. Já quanto à revista, observa-se que 32\% afirmam ter o costume de ler este produto ao longo do mês, enquanto $66 \%$ tendem a ler a revista tão $\operatorname{logo}$ a recebem em casa. Isso denota que o público entrevistado tem um alto envolvimento com os produtos avaliados, sendo, portanto, capaz de emitir opiniões bastante fidedignas quanto a estes.

\section{ANÁLISE DOS DADOS}

\section{1- Análise Exploratória, da Confiabilidade e Validade dos Dados}

No total de 487 questionários iniciais, foram encontrados 3.144 dados ausentes nas variáveis de interesse do modelo, representando $19 \%$ da base. Notavelmente tais ocorrências estavam concentradas nas páginas que os respondentes deixaram de responder, demonstrando que nenhum processo sistemático fora determinante dos padrões de dados ausentes encontrados (Tabachnick \& Fidel, 2001). Assim, esse problema foi reduzido a 99 dados ausentes com a exclusão de 130 questionários que continham 18 ou mais respostas em branco. Dados omissos remanescentes foram repostos segundo um procedimento de regressão considerando os indicadores de valor como variáveis independentes, com o intuito de evitar um incremento na correlação entre os construtos satisfação e lealdade e manter níveis adequados de variabilidade nas variáveis com dados ausentes.

Revista de Administração e Inovação, São Paulo, v. 11, n.1, p.06-28, jan./mar. 2014. 
Usando uma probabilidade de $0,1 \%$, identificaram-se 29 outliers univariados e 19 outliers multivariados, segundo o critério Z (normal padrão) e $\mathrm{D}^{2}$ (distância de Mahalanobis) respectivamente. Fundamentado nas sugestões de Kline (1998), cinco valores extremos univariados foram substituídos por valores menos ofensivos e 15 outliers multivariados remanescentes foram excluídos da análise, reduzindo a base a um total de 342 casos. Conforme testes K-S de avaliação da normalidade e Z de testes de assimetria e curtose, ficaram patentes desvios da normalidade das variáveis tratadas no estudo (Mingoti, 2005).

Em seguida procedeu-se à avaliação da unidimensionalidade das escalas por meio da AFE (extração por componentes principais) conforme sugerem Gerbing e Anderson (1988), tendo sido encontradas soluções unidimensionais para todos os construtos, tanto para o site quanto para a revista, tendo o percentual de variância explicada ficado superior a 60\% (Hair, Anderson, Tatham \& Black, 1998) em todos os casos. Em especial nota-se que a escala de lealdade, ao testar o conjunto de indicadores da lealdade de Oliver (1999), encontrou soluções unidimensionais tanto para a revista quanto para o site. Isso é um indício de que, neste estudo ao menos, não foi suportada a existência de quatro dimensões distintas de lealdade conforme propõe o referido autor.

Para avaliar a consistência interna das escalas, utilizou-se a medida alfa de cronbach cujos resultados foram: Valor como Excelência - Revista $(0,62)$, Valor como Excelência - Site $(0,81)$, Valor como Eficiência - Revista (0,66), Valor como Eficiência - Site (0,76), Lealdade - Revista $(0,92)$ e lealdade Site $(0,95)$. Esses valores indicam índices moderados de confiabilidade conforme padrões sugeridos por Hair et al. (1998).

A fim de obter evidências de validade convergente (convergent validity) do modelo, empregouse um modelo de Análise Fatorial Confirmatória (Confirmatory Factor Analysis) conforme sugerem Bagozzi, Yi e Philips (1991). Para o ajuste da AFC (CFA) foram empregados modelos de duas ondas (two wave models); trata-se de um procedimento que se presta à análise de variáveis mensuradas repetidamente no mesmo conjunto de indivíduos (Jöreskog \& Sörbom, 1989). Conforme salienta Kline (1998), o ajuste de dados longitudinais usualmente assume a correlação entre os erros de mensuração dos indicadores medidos repetidamente, indicando que existem causas comuns nos erros de mensuração desses indicadores. Assim, ajustando um modelo de erros de mensuração correlacionados por meio de mínimos quadrados generalizados (Generalized least Squares), atestou-se que os indicadores continham cargas significativas com seus construtos ao nível de 1\%, apresentando indícios da validade convergente do modelo.

Finalmente, para atestar a validade discriminante do modelo, usou-se o teste de diferença quiquadrado sugerido por Bagozzi et al. (1991). O procedimento sugere comparar o ajuste de modelos 
que assumem a correlação perfeita entre construtos com modelos que assumem que os construtos são distintos, mas correlacionados. Ao verificar a diferença da estatística qui-quadrado entre esses modelos, foi possível atestar que todos os pares de construtos apresentam evidências de validade discriminante ao nível de significância de $1 \%$.

\subsection{Teste do modelo hipotético de pesquisa}

Para testar o modelo hipotético de pesquisa deste estudo, empregou-se a técnica de modelagem de equações estruturais com uma abordagem de modelos de duas ondas (two wave models). $\mathrm{O}$ procedimento concebido visava identificar diferenças existentes entre o modelo de lealdade da revista e do site. Para identificar tais diferenças, seguiu-se o procedimento proposto por Kline (1998). Inicialmente um modelo que continha os construtos de valor, satisfação e lealdade da revista e do site. Conforme expresso anteriormente, em tal modelo se assume que as avaliações realizadas pelos respondentes para os dois objetos (revista e site) estavam correlacionadas, conforme é usual no caso de análises de dados longitudinais (Jöreskog \& Sörbom, 1989). Além disso, tratou-se de correlacionar os erros de previsão (zeta) do construto lealdade, para indicar que tais construtos compartilham ao menos uma única causa latente omitida (Kline, 1998). Finalmente, para o construto satisfação, mensurado com somente um indicador, foi necessário fixar a variância do erro.

Tomou-se a estatística qui-quadrado do modelo irrestrito (unconstrained model), em que todos os parâmetros são diferentes para a revista e o site, como a base de comparação dos modelos seguintes. Em sequência restrições sobre a igualdade dos parâmetros básicos do modelo do Site e da revista foram impostas, gerando modelo com maior número de graus de liberdade, mas ajuste deteriorado. Fazendo a comparação do ajuste dos modelos restritos (restricted models) e do modelo irrestrito, foi possível determinar quais diferenças existem entre os modelos do site e da revista, conforme resultados da Tabela 1. 
Tabela 1 - Teste de avaliação das diferenças entre os modelos: revista e site

\begin{tabular}{lccccc}
\hline \hline MODELO & $\chi^{2}$ & DF & $\chi^{2}$ DIF & DF $_{\text {DIF }}$ & SIG. \\
\hline Irrestrito (baseline model) & 905,93 & 438 & & & \\
Cargas dos construtos exógenos (valor e satisfação) & 907,85 & 441 & 1,92 & 3 & 0,59 \\
Cargas dos construtos endógenos (lealdade) & 926,38 & 448 & 20,45 & 10 & $0,03^{*}$ \\
Erros de mensuração indicadores & 1176,88 & 454 & 270,95 & 16 & $0,00^{*}$ \\
Variâncias de construtos exógenos & 908,10 & 440 & 2,17 & 3 & 0,34 \\
Correlações idênticas entre os construtos exógenos & 917,99 & 441 & 12,06 & 3 & $0,01^{*}$ \\
Valor com Eficiência $\leftrightarrow$ Valor com Excelência & 909,69 & 439 & 3,76 & 1 & $0,05^{*}$ \\
Valor com Excelência $\leftrightarrow$ Satisfação & 912,78 & 439 & 6,85 & 1 & $0,01^{*}$ \\
Valor com Eficiência $\leftrightarrow$ Satisfação & 905,93 & 439 & 0,00 & 1 & 0,96 \\
Relações estruturais & 917,12 & 441 & 11,19 & 3 & $0,01^{*}$ \\
Valor com Eficiência $\rightarrow$ Lealdade & 910,73 & 439 & 4,80 & 1 & $0,03^{*}$ \\
Valor com Excelência $\rightarrow$ Lealdade & 908,51 & 439 & 2,58 & 1 & 0,11 \\
Satisfação & 910,49 & 439 & 3,66 & 1 & $0,05^{*}$ \\
\hline \hline
\end{tabular}

Observações: $\chi^{2}$ corresponde ao qui-quadrado do modelo, DF corresponde ao número de graus de liberdade do modelo. $\mathrm{O}$ valor $\chi_{\text {DIF }}^{2}$ a diferença entre o qui-quadrado do modelo de base e o modelo em teste e o valor $\mathrm{DF}_{\mathrm{DIF}}$ é a diferença em graus de liberdade do modelo. O valor SIG. corresponde ao teste de que diferença do ajuste dos modelos. Os valores marcados com * indicam que não existe equivalência nos parâmetros testados dos respectivos modelos.

Fonte: Elaborado pelos autores.

$\mathrm{Na}$ Tabela 1 são notáveis diferenças significativas entre os modelos da revista e do site. Inicialmente nota-se que o construto lealdade tem cargas fatoriais diferentes para os dois casos, demonstrando que a lealdade dos leitores para com a revista e o site se manifesta de maneiras diferentes. Outra diferença notável corresponde aos erros de mensuração dos indicadores do modelo do site e da revista. Observando a medida de variância média extraída dos construtos, fica notável que os indicadores do site fornecem resultados mais confiáveis do que os obtidos para a revista.

Após a averiguação da igualdade dos parâmetros entre os modelos, testou-se um modelo por meio dos estimadores de mínimos quadrados generalizados, devido à maior robustez desse método a desvios da normalidade multivariada quando se tem amostras de tamanho moderado (Tabachnick \& Fidel, 2001). Um sumário desses resultados pode ser visto na Figura 3. 

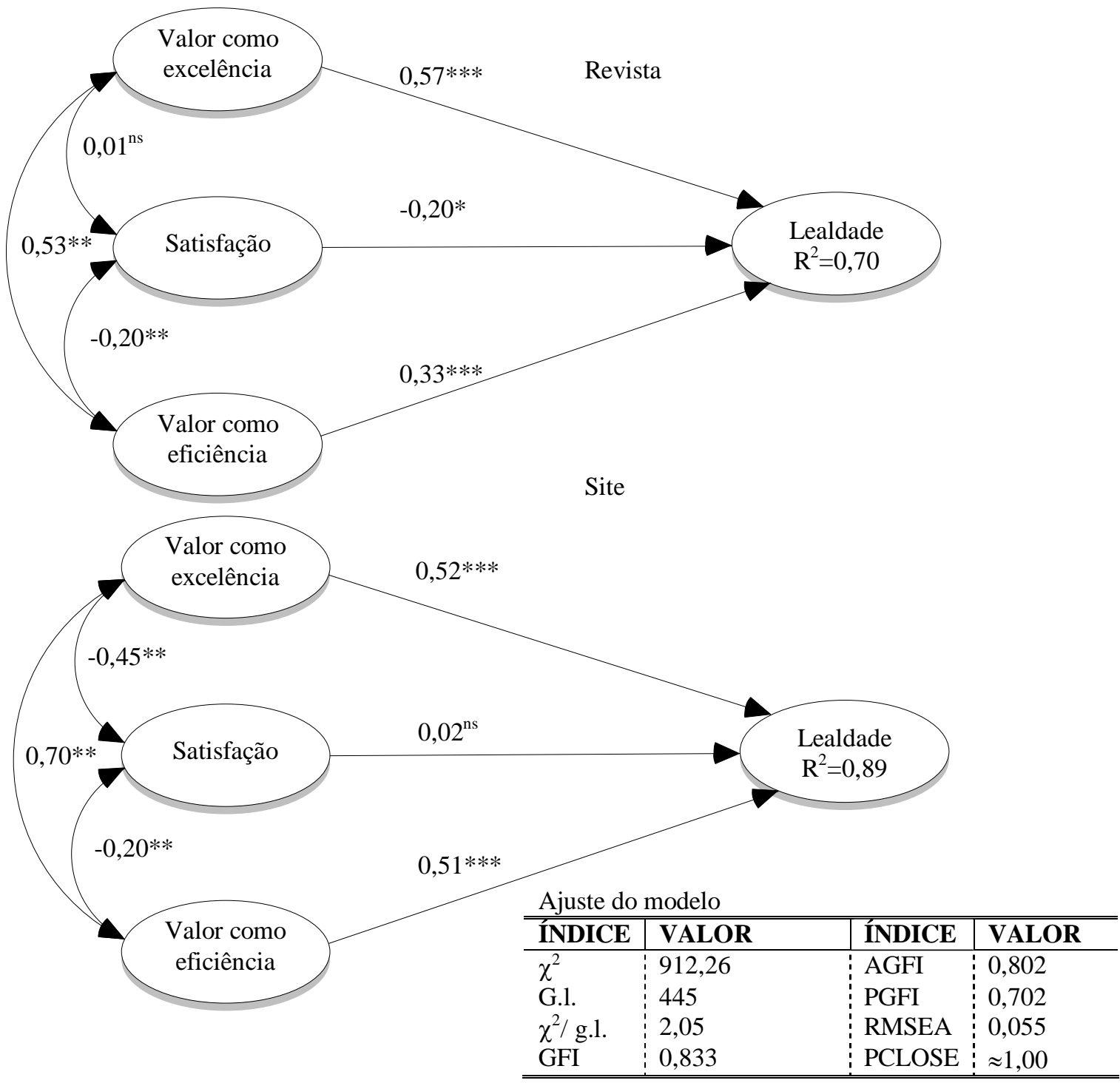
Figura 3 - Modelo hipotético de pesquisa: Relações estruturais Fonte: Elaborado pelos autores.

Observações: os valores apresentados junto às setas indicam o valor das cargas padronizadas. É necessário cautela ao comparar as cargas dos dois grupos (KLINE, 1998), pois são notáveis diferenças entre as variabilidades do construto lealdade: a variabilidade da lealdade do site é inferior à variabilidade da revista. NS indica uma carga não significativa $(\mathrm{P}>0,05)$. ** indica a significância ao nível de $1 \%(\mathrm{p}<0,01)$; *** indica a significância ao nível de $0,1 \%(\mathrm{p}<0,001)$. O Valor $\mathrm{R}^{2}$ indica o percentual de variância explicada dos construtos endógenos.

Na Figura 3 nota-se a existência de um ajuste moderado dos dados, o que é resultado do aumento na estatística qui-quadrado devido aos desvios da normalidade multivariada (Jöreskog \& Sörbom, 1989). Por isso, o valor do ajuste absoluto (GFI), ajustado (AGFI) e parcimonioso (PGFI) se enquadra em níveis abaixo dos recomendados de 0,90 (KLINE, 1998). Não obstante, o qui-quadrado normalizado $\left(\chi^{2} / g .1\right.$. ) ficou bem próximo ao limite sugerido de dois pontos, demonstrando um ajuste razoável dada a complexidade do modelo testado (Hair et al., 1998). Evidências similares podem ser 
extraídas do valor RMSEA que é inferior a 0,08 e tem uma probabilidade (PCLOSE) de aproximadamente $100 \%$ de ser inferior a este valor de corte. Não foram encontrados valores ofensivos no modelo (Heywood cases), tais como variâncias não significantes ou negativas. Assim, sugere-se que, apesar de o ajuste deste modelo não atingir os patamares usualmente sugeridos (Tabachnick \& Fidel, 2001), é possível usar o modelo em questão para analisar as relações, ao menos, na amostra/caso em estudo.

\section{CONCLUSÕES}

Cabe, aqui, resumir as avaliações das três hipóteses em relação às duas dimensões do produto. Na versão impressa e revista, nota-se uma equivalência entre os pesos do valor como excelência sobre a lealdade. Nota-se que no caso do site, a satisfação não exerceu efeito significativo sobre a lealdade. Além disso, a satisfação exerceu um efeito negativo sobre a lealdade no caso da revista, fato que contraria as hipóteses do estudo. Aventa-se a hipótese de que, à medida que o leitor se torna mais satisfeito com o produto, seu maior conhecimento sobre o cuidado e o natural crescimento com os filhos revertam-se em menor intenção de continuar a utilizar a revista. Outra possibilidade reflete-se em uma possível migração do uso da revista impressa pela sua versão eletrônica entre os usuários que apresentam maiores vínculos afetivos (satisfação) com a versão impressa. Notadamente trata-se de possibilidades que merecem ser examinadas por estudos exploratórios ou conclusivos adicionais, devendo ser vistas com cautela por contrariar um grande escopo de pesquisas na área de comportamento do consumidor (Cronin \& Taylor, 1992; Fornell,1992; Labarbera \& Mazursky, 1983; Puga et al., 2008).

Outro fato interessante notado foi a diferença expressiva entre o peso do valor como eficiência sobre a lealdade para revista impressa e eletrônica. Notou-se uma relação claramente superior para a versão eletrônica em relação à versão impressa. Destaca-se que o valor como eficiência refere-se ao valor gerado durante a experiência de consumo, sendo permeado especialmente por conceitos de conveniência (Holbrook, 1994). Isso desponta duas conclusões congruentes com proposições teóricas e práticas de que a facilidade de acesso e uso da versão impressa culminaria em maior lealdade de forma mais proeminente que a versão impressa. Em termos da estratégia de diversificação de linhas, tais resultados demonstram facilidade de acesso ao site, ponto crucial de sua utilidade e uso. Por outro lado, na revista, de atualização e abrangência limitada, a percepção prévia da excelência (valor como excelência) seria o principal norteador da lealdade, sendo a experiência de consumo (leitura) menos relevante na construção do relacionamento.

Revista de Administração e Inovação, São Paulo, v. 11, n.1, p.06-28, jan./mar. 2014. 
Tais resultados revelam que o conceito de produto ampliado deve ser gerenciado de maneira a conceber as diferentes formas que os produtos e serviços secundários são percebidos pelo consumidor. De fato existem evidências de que as estratégias que geram lealdade em determinadas dimensões do produto podem ser menos eficazes em outras formas de interação com o consumidor. Neste estudo, o Valor com a Eficiência exerceu maior impacto sobre a lealdade nos meios eletrônicos do que no meio impresso. Deste modo a acessibilidade e a interatividade com maior presença na versão eletrônica emergiriam como um moderador (intensificador) da lealdade, gerando uma distinção do papel do valor como eficiência nos meios impresso e eletrônico. Trata-se de uma hipótese a ser investigada em estudos futuros.

Ainda quanto às limitações da pesquisa, pode-se salientar que o uso de uma amostra de conveniência da população limita a possibilidade de generalização dos resultados. Finalmente pode-se sugerir que o uso de somente um indicador para avaliar o construto satisfação limita a possibilidade de testar a confiabilidade e validade deste construto, podendo exercer um impacto significativo sobre as estimativas obtidas neste estudo. Sugere-se o uso de escalas de satisfação aceitas no âmbito para verificar a estabilidade das conclusões obtidas neste estudo.

\section{REFERÊNCIAS}

Bagozzi, R., Yi, Y., \& Philips, L. W. (1991). Assessing construct validity in organizational research. Administrative Science Quarterly, 36(3), 421-458.

Barsh, J., Lee, G. S.-C., \& Miles, A. (1999). Beyond print: a future for magazines. The McKinsey Quarterly, 3, 122-130.

Berry, L., Carbone, P., \& Haeckel, H. (2003). O consumidor e as experiências. HSM Management, 2(37), 74-79.

Berry, L. L., \& Parasuraman, A. (1991). Marketing services: competing through time. New York: The Free Press.

Breitenbach, C. S., \& Van Doren, D. C. (1998). Value-added marketing in the digital domain: enhancing the utility of the internet. Journal of Consumer Marketing, 15(6), 558-575.

Cole, J. I., Suman, M., Schramm, P., Zhou, L., \& Salvador, A. (2013). The 2013 digital future report: surveying the digital future - year four. Los Angeles: University of Southern California.

Cronin J. J., Jr, \& Taylor, S. A. (1992). Measuring service quality: a reexamination and extension. Journal of Marketing, 56(3), 55-68.

Dimmick, J., Chen, Y., \& Li, Z. (2004). Competition between the internet and traditional news media: the gratification-opportunities niche dimension. The Journal of Media Economics, 17(1), 19-33.

Revista de Administração e Inovação, São Paulo, v. 11, n.1, p.06-28, jan./mar. 2014. 
Dutta, S., Dhingra, A., Buisson, P.-Y., Gil-Casares, M. M., \& Raynaud-Lacroze, P.-O. (2001). Newspapers going online: a new challenge for old media (INSEAD Working Paper Series). Fontainebleau, FR: Insead.

Eggert, A., \& Ulaga, W. (2002). Customer perceived value: a substitute for satisfaction in business market? Journal of Business \& Industrial Marketing, 17(2/3), 107-118.

Fornell, C. (1992). A national customer satisfaction barometer: the Swedish experience. Journal of Marketing, 56(1), 6-21.

Gerbing, D. W., \& Anderson, J. C. (1988). An updated paradigm for scale development incorporating unidimensionality and its assessment. Journal of Marketing Research, 25(2), 186-192.

Gren, F., Maor, D., \& Ubiñas, L. A. (2001). Late edition: another chance for newspapers on the web. The McKinsey Quarterly, 2, 74-81.

Grönroos, C. (1997). Value-driven relational marketing: from products to resources and competencies. Journal of Marketing Management, 13, 407-419.

Hair, J., Jr, Anderson, R. E., Tatham, R. L., \& Black, W. (1998). Multivariate data analysis (5 ${ }^{\text {th }}$ ed.). New Jersey: Prentice Hall.

Holbrook, M. B. (1994). The nature of customer value: an axiology of service in consumption experience. In R. T. Rust, \& R. L. Oliver (Eds.), Service quality: new directions in theory and practice (pp. 21-71). Thousand Oaks: Sage.

Jöreskog, K. G., \& Sörbom, D. (1989). LISREL® 7: a guide to the program and applications (2 ${ }^{\text {nd }}$ ed.). Uppsala, SE: SPSS.

Kline, R. B. (1998). Principles and practice of structural equation modeling. New York: The Guilford Press.

Kordupleski, R., \& Simpson, J. (2003). Mastering customer value management: the art and science of creating competitive advantage. An Arbor: Malloy Lithographing.

Kotler, P., \& Keller, K. L. (2012). Marketing management $\left(14^{\text {th }}\right.$ ed.). Upper Saddle River: Pearson Education.

Labarbera, P. A., \& Mazursky, D. (1983). A longitudinal assessment of consumer satisfaction/dissatisfaction: the dynamic aspect of the cognitive process. Journal of Marketing Research, 20(4), 393-404.

Lebo, H. (2004). First release of findings from the UCLA world internet project shows significant 'digital gender gap' in many countries. Recuperado em 04 de fevereiro, 2005, de http://newsroom.ucla.edu/portal/ucla/First-Release-of-Findings-From-4849.aspx.

Malhotra, N. K. (2012). Pesquisa de marketing: uma orientação aplicada (6a ed.). Porto Alegre: Bookman.

Mingoti, S. (2005). Análise de dados através de métodos de estatística multivariada: uma abordagem aplicada. Belo Horizonte: UFMG. 
Morgan, R. M., \& Hunt, S. H. (1994). The commitment - trust theory of relationship marketing. Journal of Marketing, 58(3), 20-38.

Mori Research. (2004). Power user 2004: reaching influentials \& influencing purchases via newspaper websites. Recuperado em 04 de fevereiro, 2005, de http://www.moriresearch.com/news/download/NAA_report.pdf.

Newell, F. (2002). Loyalty.com: customer relationship management in the new era of internet marketing. Nova York: McGraw-Hill Trade.

Newman, J. W., \& Werbel, R. A. (1973). Multivariate analysis of brand loyalty for major household appliances. Journal of Marketing Research, 10(4), 404-409.

Oliver, R. L. (1999) Value as excellence in the consumption experience. In M. B. Holbrook (Ed.), Consumer value: a framework for analysis and research (pp. 43-62). London: Routledge.

Pine II, B. J., \& Gilmore, J. H. (1999). The experience economy: the experience economy - work is theater \& every business a stage. Boston: Harvard Business School.

Puga, A. H., Hanna, A. K., Monteiro, P. R. R., \& Veiga, R. T. (2008). Satisfaction, value and loyalty in the consumption experience. Academia: Revista Latinoamericana de Administración, 41, 33-47.

Ravald, A., \& Grönroos, C. (1996). The value concept and relationship marketing. European Journal of Marketing, 30(2), 19-30.

Rayport, J. F., \& Sviokla, J. J. (1995). Exploiting the virtual value chain. Harvard Business Review, 73(6), 75-85.

Reichheld, F. (1993). Loyalty-based Management. Harvard Business Review, 71(2), 64-73.

Ribeiro, Á. H. P. (2005). Retorno financeiro dos investimentos em marketing: uma aplicação do modelo ROQ. Revista de Administração e Inovação, 2(1), 103-121.

Rossiter, J. R. (2002). The C-OAR-SE procedure for scale development in marketing. International Journal of Research in Marketing, 19(4), 305-335.

Rust, R. T., \& Zahorik, A. J. (1993). Customer satisfaction, customer retention and market share. Journal of Retailing, 69(2), 193-215.

Rust, R. T., \& Zahorik, A. J., \& Keiningham, T. L. (1995). Return on quality (ROQ): making service quality financially accountable. Journal of Marketing, 59(2), 58-70.

Steenkamp, J. E. B. M., \& Geyskens, I. (2012). Transaction cost economics and the role of national culture: a test of hypotheses based on Inglehart and Hofstede. Journal of the Academy of Marketing Science, 40(2), 252-270.

Swaddling, D. C., \& Miller, C. (2002). Don't measure customer satisfaction. Quality Progress, 35(5), 62-67.

Tabachinik, B. G., \& Fidell, L. S. (2001). Using multivariate statistics ( ${ }^{\text {rd }}$ ed.). New York: HarperCollins. 
Woodruff, R. B. (1997). Customer value: the next source for competitive advantage. Journal of the Academy of Marketing Science, 25(2), 139-153.

Zeithaml, V. A. (1998). Consumer perceptions of price, quality and value: a means-end model and synthesis and evidence. Journal of Marketing, 52(3), 2-22.

Zeithaml, V. A., \& Bitner, M. J. (2003). Marketing de serviços: a empresa com foco no cliente (2a ed.). Porto Alegre: Bookman.

\section{PRINT AND ELECTRONIC MEDIA: AN ANALYSIS FROM THE PERSPECTIVE OF CUSTOMER VALUE IN PRODUCT MANAGEMENT}

\section{ABSTRACT}

This study sought to understand the consumer behavior regarding the value generated by printed and electronic versions of a magazine, seeking to understand how the nature of the information provided about by these complementary product contribute to the loyalty and satisfaction of these consumers. The methodology applied and described throughout this paper, was based on a case study in a journal of the Brazilian market, using a conclusive approach. A sample composed by 487 magazine subscribers were surveyed and preliminary findings depict that the electronic version of the magazine, in isolation, it is still a low valued product to the readers. Moreover, it was found that the electronic version adds value to the printed version and is valued by most subscribers to the magazine printed. The electronic version appears as a complementary product to the printed product and not a replacement product. The study also showed that the hypothetical model of relationships between value, satisfaction and loyalty are consistent with theory showing reasonable correlation between these two product dimensions.

Keywords: Value; Loyalty; Product management.

Data do recebimento do artigo: 06/05/2013

Data do aceite de publicação: 20/12/2013

Revista de Administração e Inovação, São Paulo, v. 11, n.1, p.06-28, jan./mar. 2014. 